\title{
Dextro-transposition of the great arteries: switching the switch
}

\author{
Marie-A Chaix, Paul Khairy \\ Montreal Heart Institute Adult Congenital Center, Université de Montréal, Montreal, Canada \\ Correspondence to: Dr. Paul Khairy. Montreal Heart Institute Adult Congenital Center, Montreal Heart Institute, 5000 Belanger St. E., Montreal, QC \\ H1T 1C8, Canada. Email: paul.khairy@umontreal.ca. \\ Provenance: This is an invited article commissioned by the Section Editor Xicheng Deng (Department of Cardiothoracic Surgery, Hunan Children's \\ Hospital, Changsha, China). \\ Comment on: Kiener A, Kelleman M, McCracken C, et al. Long-Term Survival After Arterial Versus Atrial Switch in d-Transposition of the Great \\ Arteries. Ann Thorac Surg 2018;106:1827-33.
}

Submitted May 02, 2019. Accepted for publication May 14, 2019.

doi: $10.21037 /$ tp.2019.05.01

View this article at: http://dx.doi.org/10.21037/tp.2019.05.01

Dextro-transposition of the great arteries (D-TGA), whether isolated (simple) or associated with other congenital cardiac lesions (complex), is prevalent in 0.2 per 1,000 live births and accounts for $5 \%$ to $7 \%$ of congenital heart defects $(1,2)$. Management of D-TGA epitomizes the remarkable strides achieved in medical and surgical therapy over time in the broader field of congenital heart disease. From the original palliative Blalock-Hanlon septectomy to the modern-day arterial switch operation (ASO), the stepwise progress reflects an international success story marked by 65 years of ingenuity, innovation, and collaboration (3).

D-TGA was initially described by Baillie in 1797 (4). In 1950, Blalock and Hanlon reported an atrial septectomy approach to palliation after Blalock's assistant had creatively developed an atrial septal defect model in a mouse (5). Surgical atrial septectomy was subsequently replaced by balloon atrioseptostomy, as described by Rashkind and Miller in 1966 (6). Meanwhile, in Chicago in the 1950s, Baffes pioneered a surgical procedure with an aortic homograft to direct flow from the inferior vena cava to the left atrium, while anastomosing the right pulmonary veins to the right atrium (7). The first successful atrial switch procedure was performed in Sweden by Senning in 1957 using atrial flaps (8). In 1963, Mustard in Toronto pioneered an atrial switch surgery using pericardium (9). The next surgical milestone was in 1975 by Jatene in Sao Paulo, Brazil. The ASO was performed in 7 patients, 5 of whom died during the index hospitalization (10). The major issue consisted of optimally transferring coronary arteries, which subsequently inspired the Leiden classification of coronary anomalies (11). In 1981, Lecompte in Paris described an important technical modification that was later adopted world-wide, the "Lecompte maneuver", in which the pulmonary trunk was transferred anterior to the aorta while avoiding a prosthetic conduit (12). In a case series published in 1984 by the Boston team, ASO was performed during the first month of age thereby demonstrating the ability of a neonatal left ventricle to sustain a systemic circulation (13).

Prior to the Blalock-Hanlon septectomy (5), most children with D-TGA died during the first month of life. Survival was somewhat better in patients with an associated ventricular septal defect (14). Atrial switch surgery became the procedure of choice for D-TGA until it was progressively supplanted by the ASO in the 1980s to early 1990s. Today, $>60 \%$ of patients with D-TGA and Senning or Mustard baffles remain alive at 30 years of follow-up (15). In the Annals of Thoracic Surgery, Kiener and colleagues compared survival with ASO versus atrial switch surgery for D-TGA that was undertaken between 1982 and 1991 (16). The initial study period involved only the atrial switch, whereas at the end of the study period, $90 \%$ of surgeries were ASO. The retrospective study relied on the Pediatric Cardiac Care Consortium database, which regrouped 47 US centers. Follow-up data on transplantation-free survival were obtained from the National Death Index (NDI) and the Organ Procurement and Transplant Network.

The clever methodology allowed outcomes to be ascertained in a large number of patients decades after surgery. Additional strengths include the collection of detailed surgical variables and follow-up durations that 
compare favorably to single center reports $(17,18)$, with 54 of 132 (40.9\%) patients with ASO and 150 of 204 (73.5\%) with atrial switch surgery followed for $\geq 25$ years. Limitations acknowledged by the authors include the lack of follow-up data beyond deaths and transplantations. Moreover, $27 \%$ of patients had inadequate identifiers to track deaths, with differential exclusion of younger patients. The coronary anatomy, a potentially important predictor of outcomes, was missing in nearly $80 \%$ of patients. Finally, a truly contemporaneous comparison of the two surgical approaches is not feasible, since one replaced the other. Spanning a timeframe that includes the transition period between surgical approaches represents the closest approximation possible. However, doing so conservatively favors atrial switch surgery owing to years of experience in contrast to the newer ASO intervention that is subject to a learning curve.

Overall, the proportion of patients with simple $(\sim 70 \%)$ versus complex $(\sim 30 \%)$ D-TGA was similar between ASO $(\mathrm{N}=259)$ and atrial switch $(\mathrm{N}=295)$ groups. However, the prevalence of an atrial septal defect was higher and pulmonary outflow tract obstruction lower in patients with ASO. Among patients with known coronary anatomy, an abnormal pattern was noted in $16 \%$. This rate is lower than prior reports and should be interpreted within the context of a high proportion of missing data (18). Differences in age and weight at surgery, and in the proportion of patients with a prior balloon septostomy, likely reflect the nonrandomized design with an evolving timing of surgery. Transplantation-free survival in the ASO population was consistent with prior reports $(2,17,18)$. Interestingly, it was not significantly different from atrial switch surgery during the first 10 years $(82.1 \%$ vs. $76.3 \%, \mathrm{P}=0.14)$. Thereafter, transplant-free survival favored ASO, with an adjusted hazard ratio of 0.27 (95\% confidence interval: 0.09 to 0.81 , $\mathrm{P}=0.02)$. Late deaths occurred in 4 of $132(3.0 \%)$ patients with ASO, with two deemed cardiac related. In contrast, 34 of $204(16.7 \%)$ patients with atrial switch died, 23 from cardiac causes. Perioperative mortality associated with ASO was higher than atrial switch $(21.6 \%$ vs. $12.9 \%)$. Excess mortality in the early adoption phase of ASO was previously well characterized, and reached $71.4 \%$ in Jatene's initial reports (19). In a series of 400 patients with ASO performed at Boston Children's Hospital between 1983 and 1999 , the perioperative mortality rate was $15.1 \%$ during the initial 4 years and $3.9 \%$ during the last 4 years (18).
The relatively slow uptake of ASO over a decade of time reflects concerns about early mortality linked to the coronary anatomy and transfer. Some experienced surgeons still recommended atrial switch for patients with complex D-TGA into the mid-1980s in the absence of longterm follow-up data (20). The Lecompte maneuver, shift towards neonatal surgery, and refinement of the coronary transfer procedure contributed importantly to the success of ASO. In 2006, the European Congenital Heart Surgeons Association reported a $6 \%$ operative mortality rate, which was higher in patients with an associated ventricular septal defect (13\%) than simple D-TGA (3\%) (21). Villafane et al. noted $2.9 \%$ perioperative mortality with ASO from 2003 to 2007 (2). In the current era, the 20-year survival rate exceeds $90 \%(2,18)$.

In some respects, switching the switch from atrial to arterial resulted in diametrically opposed patient populations with D-TGA (Figure 1). One has a morphologic right and the other left systemic ventricle. In one, extensive atrial suture lines predispose to a high prevalence of atrial arrhythmias, whereas the other does not involve atrial surgery. Although the atrial switch has largely been relegated to a historical note in the pediatric world, adult congenital heart disease teams face unique challenges encountered in this aging population. Common complications include sinus node dysfunction, complex arrhythmias, systemic right ventricular dysfunction, tricuspid regurgitation, subvalvular pulmonary stenosis, and baffle obstructions and leaks (15,22-24). Sixty years later, under-appreciated complications such as pulmonary hypertension are being characterized (25) and research forges ahead regarding the pathophysiology and prevention of sudden cardiac death (26). With regards to ASO, despite reassuring mid-term outcomes $(2,16,18)$, it is not impervious to late complications. These include neopulmonary stenosis, neoaortic regurgitation, neoaortic root dilatation, supravalvular aortic and pulmonary stenosis, coronary artery disease, neurodevelopmental abnormalities, and chronotropic incompetence (18). Follow-up beyond the $5^{\text {th }}$ decade of life remains unknown. Early screening and lifelong management of coronary risks factors is recommended. However, the future will reveal whether this strategy effectively protects against coronary events. Although the wisdom in transitioning to ASO is no longer questioned, caregivers must not cease to learn from this first cohort of survivors and adapt management strategies accordingly, as continues to be the case for the atrial switch population. 


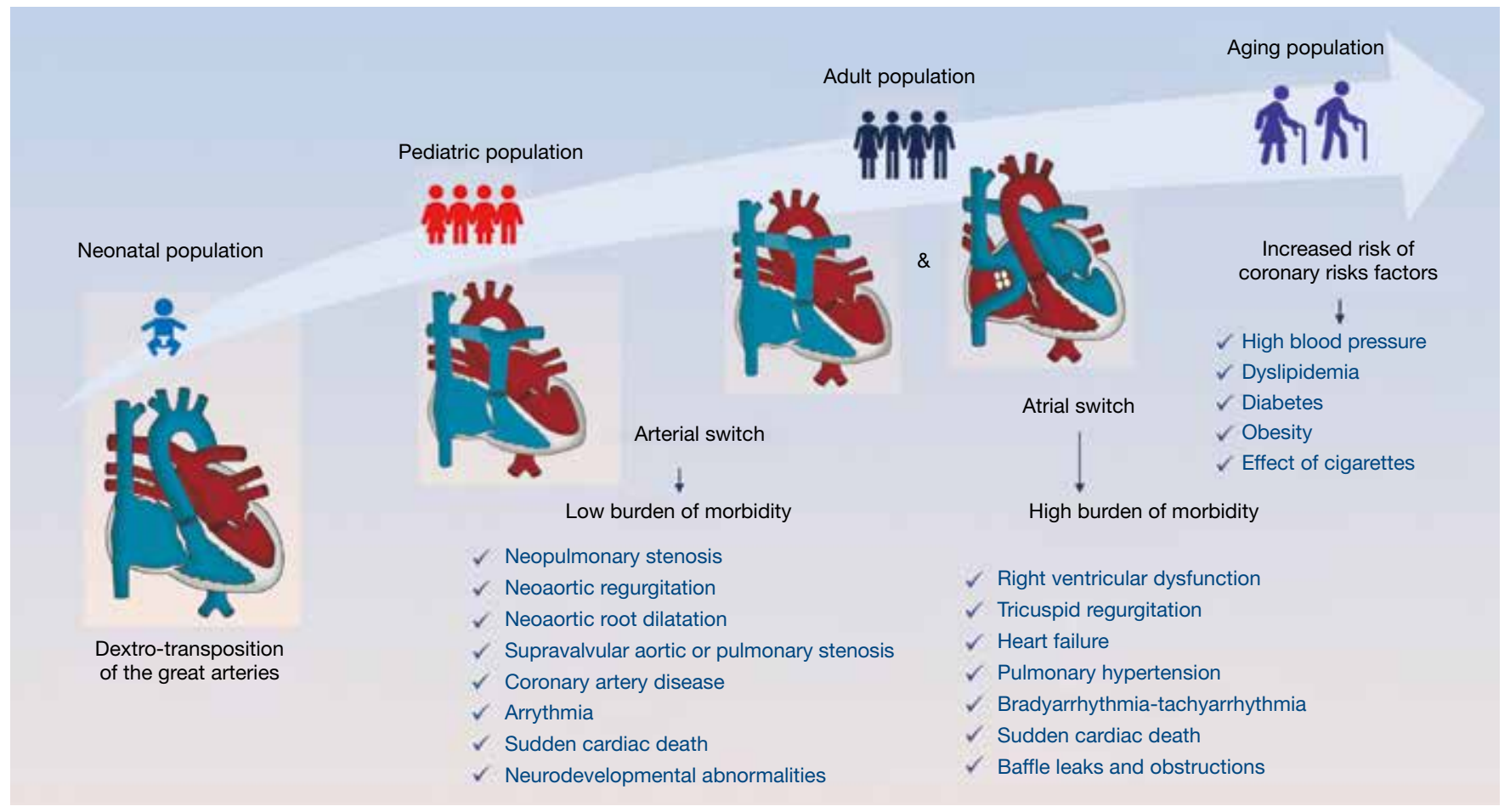

Figure 1 Challenges and outcomes over the lifespan in patients with D-TGA.

\section{Acknowledgments}

None.

\section{Footnote}

Conflicts of Interest: The authors have no conflicts of interest to declare.

\section{References}

1. van der Linde D, Konings EE, Slager MA, et al. Birth prevalence of congenital heart disease worldwide: a systematic review and meta-analysis. J Am Coll Cardiol 2011;58:2241-7.

2. Villafañe J, Lantin-Hermoso MR, Bhatt AB, et al. D-transposition of the great arteries: the current era of the arterial switch operation. J Am Coll Cardiol 2014;64:498-511.

3. Marathe SP, Talwar S. Surgery for transposition of great arteries: A historical perspective. Ann Pediatr Cardiol 2015;8:122-8.

4. Baillie M. The morbid anatomy of some of the more important parts of the human body. 2 nd edition. London:
Johnson and Nicol, 1797:38.

5. Blalock A, Hanlon CR. The surgical treatment of complete transposition of the aorta and the pulmonary artery. Surg Gynecol Obstet 1950;90:1-15, illust.

6. Rashkind WJ, Miller WW. Creation of an atrial septal defect without thoracotomy. A palliative approach to complete transposition of the great arteries. JAMA 1966;196:991-2.

7. Baffes TG. A new method for surgical correction of transposition of the aorta and pulmonary artery. Surg Gynecol Obstet 1956;102:227-33.

8. Senning A. Surgical correction of transposition of the great vessels. Surgery 1959;45:966-80.

9. Mustard WT, Keith JD, Trusler GA, et al. The Surgical Management of Transposition of the Great Vessels. J Thorac Cardiovasc Surg 1964;48:953-8.

10. Jatene AD, Fontes VF, Paulista PP, et al. Anatomic correction of transposition of the great vessels. J Thorac Cardiovasc Surg 1976;72:364-70.

11. Gittenberger-de Groot AC SU, Oppenheimer-Dekker A, Quaegebeur J. Coronary arterial anatomy in transposition of the great arteries: A morphologic study. Pediatr Cardiol 1983;4:15. 
12. Lecompte Y, Zannini L, Hazan E, et al. Anatomic correction of transposition of the great arteries. J Thorac Cardiovasc Surg 1981;82:629-31.

13. Castaneda AR, Norwood WI, Jonas RA, et al. Transposition of the great arteries and intact ventricular septum: anatomical repair in the neonate. Ann Thorac Surg 1984;38:438-43.

14. Liebman J, Cullum L, Belloc NB. Natural history of transpositon of the great arteries. Anatomy and birth and death characteristics. Circulation 1969;40:237-62.

15. Vejlstrup N, Sorensen K, Mattsson E, et al. LongTerm Outcome of Mustard/Senning Correction for Transposition of the Great Arteries in Sweden and Denmark. Circulation 2015;132:633-8.

16. Kiener A, Kelleman M, McCracken C, et al. LongTerm Survival After Arterial Versus Atrial Switch in d-Transposition of the Great Arteries. Ann Thorac Surg 2018;106:1827-33.

17. Fricke TA, d'Udekem Y, Richardson M, et al. Outcomes of the arterial switch operation for transposition of the great arteries: 25 years of experience. Ann Thorac Surg 2012;94:139-45.

18. Khairy P, Clair M, Fernandes SM, et al. Cardiovascular outcomes after the arterial switch operation for d-transposition of the great arteries. Circulation 2013;127:331-9.

19. Bull C, Yates R, Sarkar D, et al. Scientific, ethical, and logistical considerations in introducing a new operation: a retrospective cohort study from paediatric cardiac surgery.
BMJ 2000;320:1168-73.

20. Stark J. Transposition of the great arteries: which operation? Ann Thorac Surg 1984;38:429-31.

21. Sarris GE, Chatzis AC, Giannopoulos NM, et al. The arterial switch operation in Europe for transposition of the great arteries: a multi-institutional study from the European Congenital Heart Surgeons Association. J Thorac Cardiovasc Surg 2006;132:633-9.

22. Görler H, Ono M, Thies A, et al. Long-term morbidity and quality of life after surgical repair of transposition of the great arteries: atrial versus arterial switch operation. Interact Cardiovasc Thorac Surg 2011;12:569-74.

23. Moons P, Gewillig M, Sluysmans T, et al. Long term outcome up to 30 years after the Mustard or Senning operation: a nationwide multicentre study in Belgium. Heart 2004;90:307-13.

24. Cuypers JA, Eindhoven JA, Slager MA, et al. The natural and unnatural history of the Mustard procedure: long-term outcome up to 40 years. Eur Heart J 2014;35:1666-74.

25. Chaix MA, Dore A, Mercier LA, et al. Late Onset Postcapillary Pulmonary Hypertension in Patients With Transposition of the Great Arteries and Mustard or Senning Baffles. J Am Heart Assoc 2017;6. doi: 10.1161/ JAHA.117.006481.

26. Chaix MA, Chergui M, Leduc C, et al. Sudden death in transposition of the great arteries with atrial switch surgery: Autopsy evidence of acute myocardial ischemia despite normal coronary arteries. Int J Cardiol 2019;288:65-7.
Cite this article as: Chaix MA, Khairy P. Dextro-transposition of the great arteries: switching the switch. Transl Pediatr 2019;8(5):458-461. doi: 10.21037/tp.2019.05.01 